\title{
What is 'footprint' in Antarctica: proposing a set of definitions
}

\author{
SHAUN T. BROOKS ${ }^{1}$, JULIA JABOUR ${ }^{1}$ and DANA M. BERGSTROM ${ }^{2}$ \\ ${ }^{1}$ Institute for Marine and Antarctic Studies, University of Tasmania, Hobart, Tasmania, Australia \\ ${ }^{2}$ Australian Antarctic Division, 203 Channel Highway, Kingston, Tasmania, Australia \\ stbrooks@utas.edu.au
}

\begin{abstract}
Footprint has become a common term in environmental research in Antarctica, yet after 25 years there is still no certainty about what it refers to. In relation to Antarctica, the closest definition has been 'the spatial extent and intensity of disturbance'. Yet there is still confusion around what a 'disturbance' footprint is actually measuring. This is evident within Committee for Environmental Protection documents, in which there have been over 80 mentions of footprint, with at least eight different meanings, since 1998. To improve clarity in its use by both scientists and policymakers, we first examine the development of the term footprint, how it has been applied, and its usefulness in applications such as interpreting 'minor or transitory' activities. We then identify and define a suite of footprint types (disturbance, building, contamination, non-native species, noise, visual, visitation, risk, carbon, ecological, and human), with the aim of developing a common understanding of what the term refers to. Our goal is to ensure the concept of footprint can be a useful environmental tool to facilitate progressing environmental protection.
\end{abstract}

Received 20 October 2017, accepted 10 April 2018, first published online 13 June 2018

Key words: contamination, disturbance, environmental impacts, tourism, wilderness

\section{Introduction}

Globally the use of the term footprint to describe the spatial nature of environmental impacts has increased exponentially since it appeared in Rees (1992). This ecological footprint quantified a human population's resource consumption and waste assimilation requirements into a theoretical land area (e.g. 4.9-5.9 hectares per capita required in the case of Vancouver, Canada, Rees 1992). Carbon footprint, which emerged in the mid-2000s, built upon this concept, but this described greenhouse gas output, measured in tonnes (Wiedmann \& Minx 2008), drifting from the original use of footprint as a spatial quantification.

Although carbon and ecological footprints are still the dominant forms of footprint in the broader literature, use of the term footprint has developed a different emphasis in Antarctica, with many different meanings. Walton \& Shears (1994) first identified a need to quantify the footprint of human activities on the environment as a major requirement to improve environmental management. This use of the term footprint was a departure from the use of the term elsewhere and described quantifying localized impacts on the environment derived from data. The term footprint has now been in continued use in relation to Antarctica but despite almost 25 years passing and significant environmental progress, most notably with the Protocol on Environmental Protection to the Antarctic Treaty (Madrid Protocol) entering into force in 1998, there is still no clear agreed use of the term. This is despite footprint measurements offering a valuable tool for science and policy to assist parties to the Antarctic Treaty in understanding environmental impacts and protecting the Antarctic environment, as required under the Madrid Protocol.

In an attempt to define the term within policy discussions, two Information Papers provided to the Committee for Environmental Protection (CEP) (established to provide advice and formulate recommendations in connection with the implementation of the Madrid Protocol) compiled 85 references to footprint within CEP documents to 2014 (ASOC 2014, Australia 2010). Within these documents at least eight different types of footprint are referred to, ranging from surface disturbance to carbon emissions, and applying to national programmes through to tourism. Furthermore, footprint has been used as a figurative term to describe a range of environmental impacts. Thus the term has been used frequently within Antarctic policy and literature and to help clarify its future application this paper reviews the range of previous uses of the term footprint in Antarctica and offers some recommendations for standardization of use.

\section{Monitoring baseline or communication tool?}

A fundamental consideration in determining what a footprint measures is to ask for what purpose the measurement is to be used. Scientifically footprint is arguably the most direct approach to presenting spatial and temporal baselines of the state of the environment around local human activities in Antarctica, which can then be used as the point from which to monitor environmental impacts. Examples are summarized in Hull \& Bergstrom (2006) and Tin et al. (2009). A long-term footprint 


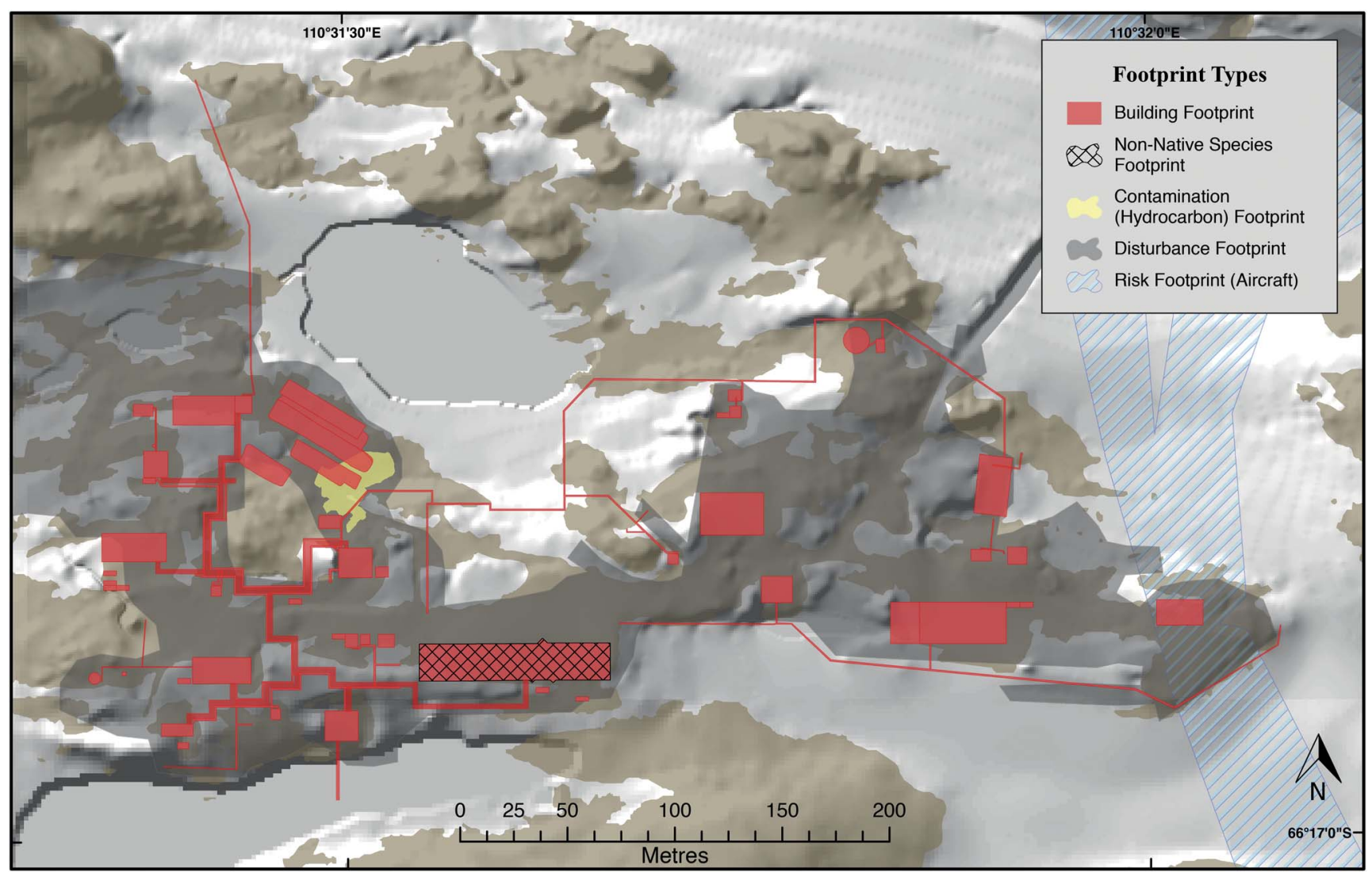

Fig. 1. Example application of five subcategories of footprint mapped around Australia's Casey Station, Antarctica (note these footprint layers are for illustrative purposes only and may not reflect the actual footprint at this station). Horizontal Datum: WGS84. Projection: UTM Zone 49S. Building, digital elevation model, aircraft approaches, and exposed rock data: Australian Antarctic Division. Hydrocarbon contamination area: McWatters et al. (2016) (note this relates to a single spill). Disturbance and non-native species layers are original. Produced by S. Brooks.

monitoring project at McMurdo Station is also a good example of this, capturing impacts associated with an Antarctic station over 60 years (Klein et al. 2008, Kennicutt II et al. 2010). It has been argued that the application of a footprint approach to document human impact, such as this, should be the standard for all stations in Antarctica (Hughes 2010).

Although the McMurdo project and the original argument of Walton \& Shears (1994) was for baseline measurement and monitoring, the term footprint has also been used for communicating impacts. Footprint can communicate the scale of impacts combining a range of environmental disturbances (for example see Fig. 1). The value in communicating the scale and spread of the footprint of Antarctic activities to policymakers was a key motive for the footprint measurements of Brooks (2014), Hughes et al. (2011) and Pertierra et al. (2017). Understanding the spatial extent of impacts through footprint can assist operators in ensuring their compliance with the Madrid Protocol.

The value of establishing a footprint baseline of an operator's facilities, and communicating that understanding, can go beyond science and policy, to also inform station planners, engineers, environmental managers, regulators and authorities. Although most Antarctic programmes will undoubtedly have a wealth of knowledge about their stations and the environment they inhabit, it is ambitious to expect that an understanding of the full extent of environmental impacts is shared evenly across all operational roles. By quantifying and making available the footprint of Antarctic facilities, operators in different roles could have the means for awareness as well as a ready reference for enquiry.

\section{Footprint and Environmental Impact Assessment}

Footprint can also contribute to the implementation and understanding of the term 'minor or transitory impact' in the Madrid Protocol (Article 8.1). The vagueness of this crucial component of the Protocol helped give it flexibility to pass the complexities of international negotiations, but left interpretation open to each signatory state (Rothwell 2000, Fallon \& Kriwoken 2005). When considered in the context of footprint, the term 'minor' becomes a measure of scale, and 'transitory' a temporal measure of impact. 
When considering the term 'minor' impact, scale is meaningful only in the context of its location. Whereas one station on a continent of 14 million square kilometres (Hughes 2010) may be insignificant, one in the $0.37 \%$ or less of Antarctica that is ice-free (Burton-Johnson et al. 2016) is more significant. Of even greater significance, the majority of the stations and associated impacts occur in the just c. $0.05 \%$ of ice-free Antarctica that is within $2 \mathrm{~km}$ of the coast (Hull \& Bergstrom 2006). Recognizing that ice-free areas are biogeographically distinct rather than homogeneous (Terauds et al. 2012), the scale of a station (considering they can be greater than 250 hectares, see Klein et al. 2008) can be of significant impact in the context of that environment. Many Antarctic facilities are placed in the relatively small ice-free coastal oases or nunatak 'habitat islands' (sensu Hull \& Bergstrom 2006) so that the scaling context makes these seemingly minor impacts increase in importance.

For temporal measures of footprint the question arises 'how long is transitory?' One CEP Information Paper (New Zealand 2010) proposed that footprint be categorized as greater than, or less than, one year, based upon the associated activities being persistent or transient (acknowledging cumulative transient activities can create persistent impacts). With the exception of truly transitory events (such as tracks in snow), the impacts from non-ongoing activities should possibly be considered permanent until there is sufficient evidence to show that the receiving environment has been or will be restored to a natural state, either through natural processes or human intervention, within a finite period. For example, at Law Base in the Larsemann Hills, Goldsworthy et al. (2003) found ground that was visibly stained from greywater dumped 10 years previously. Within the Wright Valley and at Marble Point, O'Neill et al. (2013) found visible impacts from machinery from 50 years earlier. Furthermore, Kennicutt II et al. (2010) suggested disturbed surfaces at McMurdo could take tens to hundreds of years to recover. Even low intensity activities such as walking on Antarctic soils have been found to result in long-term disturbance (Campbell et al. 1998, Ayres et al. 2008). Although many Antarctic environments may have quicker rehabilitation rates than these examples, further research across substrates and climates may be needed to prove this.

\section{Does footprint need to be visible?}

The majority of footprint literature is based on measuring visible impacts. Important spatial impacts can, however, be measurable but not visible, such as hydrocarbon contamination (e.g. mapping of elevated hydrocarbons at McMurdo Station, Klein et al. 2012). Alternatively, visible impacts may have negligible effects on biota and habitat (and therefore scientific value) yet they may degrade wilderness and aesthetic values (which are also protected under the Madrid Protocol (Article 3)). New Zealand
(2010) suggested defining footprint as visible impacts, as they were easily observable and can be an indicator of further non-visible impacts such as compaction, reduced soil biota, and contamination. This is also reflected in the scientific literature, with most terrestrial studies based on visible impacts. This is supported by examples such as the Progress I station in the Larsemann Hills, where hydrocarbon contamination was detected only at sites of visible impacts (Goldsworthy et al. 2003). Conversely, it is expected that the apparent nature of visible impacts is responsible for attracting attention to them. More work is needed here, especially in different Antarctic substrates, to establish the relationship between visible disturbance and actual impacts on biota and natural processes.

\section{Absence of footprint}

Locating the full extent of footprint in Antarctica has been suggested as a method to determine inviolate and wilderness areas. New Zealand (2011) proposed that a definition of Antarctic wilderness might be 'the absence of footprint'. ASOC (2014) also noted that wilderness generally has an 'inverse relationship to footprint', but sought to avoid defining wilderness by what it is not. In relation to its scientific value, Hughes et al. (2011) proposed that the absence of visitation could be used to identify areas in need of protection to preserve inviolate areas for the future. This presence or absence of footprint was also used by Belgium et al. (2013) to highlight the importance of long-term conservation of Antarctic microbial habitats and the pressure from an ever increasing visitation footprint, especially in ice-free areas.

\section{Defining footprint}

Since the initial mention of footprint in Antarctica there have been repeated calls for developing a conceptual and spatial understanding of Antarctic footprint (Walton \& Shears 1994, United States 2003, Summerson \& Tin 2009, Hughes 2010). However, just as there will be differing values placed on the environment across (and within) cultures, the Consultative Parties to the Antarctic Treaty will all have different environmental ethics, and will place varied focus on specific values. These may include differing attitudes to the desirability of impacting wilderness, view shed (the area of visibility of infrastructure and activity), noise, contamination, energy consumption, and conspicuous or discrete facilities. These differing values between cultures may also account for the diversity of definitions of footprint. Despite the definitions provided by ASOC (2014), Jabour (2009) and New Zealand (2011), all corresponding as a measure of the spatial extent of disturbance, what disturbance is has taken on many meanings. As footprint has gained traction as a term to describe environmental impacts and pressures in Antarctica, 
Table I. Categories and subcategories of footprint.

\begin{tabular}{|c|c|c|}
\hline Category & Subcategory & References of use \\
\hline \multirow[t]{5}{*}{ Physical } & Disturbance footprint* & $\begin{array}{l}\text { Kriwoken (1991), Klein et al. (2008), United States (2008), Bollard-Breen et al. (2014), } \\
\text { Brooks (2014) }\end{array}$ \\
\hline & Building footprint* & New Zealand (2003), France (2005), United States (2007) \\
\hline & Contamination footprint* & $\begin{array}{l}\text { Howington et al. (1992), Goldsworthy et al. (2003), Roura (2004), Conlon et al. (2006), } \\
\text { Tin et al. (2009), Klein et al. (2012), Fryirs et al. (2013) }\end{array}$ \\
\hline & $\begin{array}{l}\text { Non-native species } \\
\text { footprint* }\end{array}$ & Hughes \& Worland (2010), Galera et al. (2016) \\
\hline & Noise footprint & Summerson (2012) \\
\hline \multirow[t]{3}{*}{ Non-physical } & Visual footprint & Australia (2002), Summerson \& Bishop (2012) \\
\hline & Visitation footprint & Hull \& Bergstrom (2006), Summerson \& Tin (2009), Hughes et al. (2011), Pertierra et al. (2017) \\
\hline & Risk footprint* & Chwedorzewska (unpublished), Hughes et al. (2011), AAD (2014), Pertierra et al. (2017) \\
\hline \multirow[t]{2}{*}{ Indirect } & Carbon footprint & Farreny et al. (2011), The Penguin Offset (http://www.penguinoffset.com) \\
\hline & Ecological footprint & Belgium (2006), China (2008) \\
\hline Human footprint & & Hughes et al. (2011), Pertierra et al. (2017) \\
\hline
\end{tabular}

* = examples illustrated in Fig. 1

clarification to avoid misunderstandings and facilitate discussions should help in improving environmental protection.

\section{Types of footprint}

Here are provided three categories of footprint: physical, non-physical, and indirect together with a number of defined subcategories (Table I). Physical footprints are those that can be empirically observed or measured, either visually or through sampling. These may not have easily detectable edges, with gradients dissipating until a background level is reached. Non-physical footprints are those that may not have any biological, mechanical, or chemical disturbance to the natural environment but diminish other values, including wilderness or aesthetics. Risk footprint is included with the non-physical footprints, as it only has the potential to create physical impacts. Indirect footprints are those that have global impacts but may have no detectable effects on the local environment.

\section{Physical footprints}

This category has been the predominant use of footprint in the literature. The original mentions of footprint by Walton and Shears (1994) and United States (1998) both referred to a spatial measurement of a range of physical impacts. Although a single physical 'footprint' dataset would be ideal, it would need to be produced in layers. Combining all facets of physical impacts into one footprint is problematic, as the area polluted by heavy metals measurable in snow around a station, for example, would probably be an order of magnitude greater than that of visible substrate disturbance.

\section{Disturbance footprint}

Disturbance footprint is the measure of visible substrate disturbance caused by compaction, clearing, earthworks and other landscape modification from human activities (Fig. 1) and is the dominant use of footprint in the literature and Antarctic Treaty documents. Within CEP documents at least $40 \%$ (34) of mentions of footprint were interpreted by the authors as referring to a disturbance footprint. Spatially quantifying the substrate disturbance caused by Antarctic activities predates the first mentions of footprint, such as Kriwoken (1991) highlighting the spatial area impacted by the former and current Casey Stations. Many authors, including Klein et al. (2008), Bollard-Breen et al. (2014), Brooks (2014) and Tejedo et al. (2016), have used footprint to describe areas of physical surface and landscape modification, aligning with this definition. Although visible substrate disturbance may not conclusively affect biota or indicate contamination, it has a direct impact on wilderness and aesthetic values. Work has been done on classifying the degree of substrate disturbance, and how readily it occurs and recovers in some environments (e.g. Campbell et al. 1998, O’Neill et al. 2013), but most approaches have not tackled measuring the gradients of impact that inevitably occur on the outer margins of disturbed areas.

\section{Building footprint}

Building footprint is the spatial area covered by a facility's buildings. This is common terminology in the construction and planning industry globally and is used for the same purpose in Antarctica. Footprint has been used by authors and Treaty Parties to describe the discrete total area covered by a building's perimeter (e.g. United States 2007, Davis 2017). This would be expected to create an underlying disturbance footprint through the need for foundations, disturbance during construction (Brooks 2014), and the effects of light obstruction, wind channelling and snow drifts. Use of this term is usually apparent, but it may need to be referred to as building footprint in documents in which the context is not construction/building specific. 


\section{Contamination footprint}

Contamination footprint is the area contaminated by a pollutant. This footprint may include a variable depth and concentration aspect. Footprint has been used to describe contamination of the terrestrial, nearshore, and atmospheric local Antarctic environment by organic and inorganic materials, including hydrocarbons, sewage, waste, and other pollution. It could also be used in the context of genetic pollution, where sewage outfalls and microbial contamination from human activities may impact through, for example, lateral gene transfer to native microbes (Cowan et al. 2011). This form of footprint has been used in the literature more than in CEP documents, and usually refers to a specific contaminant. Many authors (e.g. Goldsworthy et al. 2003, Roura 2004, Tin et al. 2009, Klein et al. 2012) have described the area affected by contamination as footprint. Other studies quantify the spatial area and intensity of contamination in Antarctica without referring to it as footprint (e.g. Howington et al. 1992, Fryirs et al. 2013). Contamination footprint is likely to be associated with (or within) other forms of footprint. When referring to a specific contaminant, the footprint would be best described using the contaminant in question as a prefix (e.g. hydrocarbon contamination footprint).

\section{Non-native species footprint}

Non-native species footprint is the localized area of distribution of a non-native species in Antarctica. Although footprint has not yet been used in this context in Antarctica, it may be a useful concept. The spread and density of flora and fauna populations are conventionally termed their 'distribution'. This is usually tied to species with wide geographical spread, for which it is impractical to provide a figure. However, the distribution of introduced species is more often than not localized, and point sources may be linked directly to the impacts of stations and human activity. Many studies of non-native invertebrate and flora species at sites of human activity in Antarctica have provided the conventional square metre figure (e.g. Pertierra et al. 2013). These figures are useful, but without mapping they do not communicate the spread, intensity or distribution within the natural or built environment. Some studies have mapped non-native species (Hughes \& Worland 2010, Galera et al. 2016) and these illustrate the distribution, density, and relation of introduced invertebrates and grasses within a station environment, without using the term footprint. Combining the mapping in these examples with considering the distribution of nonnative species in the context of being a direct result of human activities demonstrates how a non-native species footprint could provide a useful additional layer to assessing the environment and impacts of an Antarctic station or site.

\section{Noise footprint}

Noise footprint is an established term describing the spatial area in which noise from a source, usually above a set decibel reading, can be measured. This is most commonly used by the aeronautical industry. Noise footprint has application in Antarctica as it has a direct impact on wilderness values (Summerson 2012), and there is concern about the effects of noise on wildlife, with some evidence of affected behaviour (Tin et al. 2009). Although scientific and CEP documents have given attention to the terrestrial emission of noise from Antarctic activities, literature relating to the spatial area impacted is less common.

\section{Non-physical footprints}

Visual footprint

Visual footprint is the area of visibility of infrastructure and activity, also known as 'view shed'. Within the Madrid Protocol, the environmental principles include protection of wilderness and aesthetic significance (Article 3), and it is these values that are inherently degraded by visual footprint. Summerson and Bishop (2012) found the visual footprint of Antarctic stations and their infrastructure to have the greatest effect on such values. Most evidence indicates visual footprint affects wildlife in combination with noise and human presence, but there is limited knowledge of its effects in isolation. Visibility footprint was previously included in Australian Antarctic State of the Environment reporting (Australia 2002).

\section{Visitation footprint}

Visitation footprint refers to the land area of Antarctica that has had human presence. Although the term visitation footprint was neither explicitly found in Antarctic literature nor expressly referred to in the Madrid Protocol, 19\% (16) of mentions of footprint within CEP documents, the second highest occurrence after disturbance, were interpreted by the authors as referring to it. Tourism sites are included in this footprint, although cumulative impacts may lead to additional types of footprints (Roura 2011). Summerson \& Tin (2009) referred to this as the 'activity' component of a human footprint. Hull \& Bergstrom (2006) and Hughes et al. (2011) used footprint maps extrapolated from expedition data to indicate the visitation presence of national programmes. Pertierra et al. (2017) also used this approach, applying global footprint methodology from Sanderson et al. (2002) to infer the probable area of human visitation from Antarctic facilities. Although the environmental impacts from the majority of visited areas in Antarctica are probably below currently measurable levels, and are 'transient' (Summerson \& Tin 2009), concern has been raised regarding the risk footprint it creates for microbial contamination (Belgium et al. 2013, Hughes et al. 2015), 
non-native species, and reduction in area of reference-state natural environments (Hughes et al. 2011). Despite the value to science and management in knowing where people have been in Antarctica, as well as most contemporary expeditions maintaining global positioning system (GPS) data and transect logs, these data are seldom compiled or published.

\section{Risk footprint}

Risk footprint is the area exposed to either potential physical impacts in the event of an incident, or impacts not yet detected. Identifying and understanding threats posed to vulnerable areas through risk footprints is suggested as an avenue to reduce environmental impacts through all stages of an activity. An example of an application of this could be the 2010 emergency jettison of three fuel drums, carried by helicopter, into the catchment of Lake Dingle in the Vestfold Hills (an area frequented by wildlife and of scientific interest, see also Raymond et al. 2016). As jettisoning sling-loaded cargo from a helicopter in the event of loss of flight stability is a foreseeable occurrence, the use of a risk footprint in flight path mapping may suggest flying over less vulnerable areas. Risk footprint may also include areas exposed to impacts that are not yet fully understood or detected (including examples given within Visitation footprint). Although this term is yet to gain traction within Antarctic literature, referring to the risk of environmental impacts from the footprint of activities, especially of vectors of species introduction, is already in use (e.g. Hughes et al. 2011, Pertierra et al. 2017 and Chwedorzewska unpublished, 2010). It is believed that risk footprint is already used inherently in planning and logistics for siting infrastructure such as bulk fuel storage and potential areas of contamination in the event of a major spill.

\section{Indirect footprints}

\section{Carbon footprint}

As in other parts of the world, carbon footprint in Antarctica is a departure from a spatial measurement, and implies the greenhouse gas emission contribution from an activity or facility. The use of the term carbon footprint is usually apparent, and is most often in reference to Antarctic tourism (e.g. Farreny et al. 2011). Despite being raised within policy discussions (CEP 2010), it receives limited attention in the published literature. Although there is little room for confusion regarding the term, its predominant use outside Antarctic literature leads to other applications of footprint being mistaken for it.

\section{Ecological footprint}

Ecological footprint, using a definition similar to that of Rees (1992), refers to the resource consumption requirements of an Antarctic station. This has also been referred to as environmental footprint. Although an ecological footprint analysis could be applied to any Antarctic station, its result would be unusual given the unique nature of stations. Because of the need to import nearly all resources, the energy requirements in the extreme conditions, and the small populations, the ecological footprint of an Antarctic research station would probably appear disproportionate to elsewhere in the world. Although reducing a station's resource consumption would have flow-on effects for other forms of footprint, such as less area for fuel storage, this particular measurement, as suggested by Jabour (2009), is of limited use. Ecological footprint has been used to refer to the energy efficiency of Antarctic stations, especially new constructions (e.g. Belgium 2006, China 2008).

\section{Human footprint}

Human footprint is a combination of all categories of footprints, measuring impacts ranging from areas of influence through to, and including, heavily modified landscapes. It is also used throughout the literature as a figurative term to describe the cumulative area of activity across the continent, encompassing most forms of footprint, without reference to a measurement. Human footprint appears to be derived from the usage by Sanderson et al. (2002), presenting a global-scale approach combining disturbance, accessibility, and visitation footprints. What exactly is measured by human footprint varies in the literature. Generally it has been used to measure continentor region-wide trends and to reveal the scale of area visited by Antarctic programmes. Summerson \& Tin (2009, p. 178) provided a clear summary of their interpretation, with 'infrastructure (buildings and structures) and activity (people doing things or in transit)' being the major components. A similar interpretation (visitation and sites) has been used to map the human footprint of the British Antarctic Survey (Hughes et al. 2011), whereas Pertierra et al. (2017) took a continental approach to human footprint, applying a footprint score at set radiuses of up to $5 \mathrm{~km}$ from point locations of Antarctic stations. In other documents, human footprint has also been used to describe disturbance (e.g. Tejedo et al. 2016). The problem with combining disturbance and visitation footprints together as a measurement is that they are useful only if presented as layers or gradients that distinguish the levels of impact. Mapping together rare visitation to an area, with no measurable lasting impacts or with set buffer radiuses from facilities, with permanent landscape disturbance from a station is of limited practical management use.

\section{Discussion}

Footprint has become a regularly used description of the impact of activities in Antarctica for quantification and 
communication. The lack of clarity around the meaning of the term, demonstrated by ongoing policy discussion attempting to define footprint, makes it evident that rationalizing and consolidating terminology is required. The primary usage of footprint to date has been as a measure of the spatial extent of disturbance, but that too requires clarification. The initial application of footprint (Walton \& Shears 1994) referred to an example of snow contaminated with heavy metal emissions from a station, whereas the largest project to measure footprint (Klein et al. 2008) referred to visible terrestrial substrate disturbance. The footprints of transitory activities are also not equal, e.g. subject to the receiving environment, the disturbance footprint of a small ice-free field campsite (e.g. Bollard-Breen et al. 2014) may be evident much longer than that of a major ice tractor train expedition. More work is needed to establish restoration rates for the different Antarctic environments, as well as to determine techniques to minimize these rates initially, such as whether reusing sacrificial disturbance footprint areas is preferable to disseminating impacts over a wider area.

The reason for the varied interpretation of footprint may be attributed to the variety of motivations or purposes for the work. Combined human footprint measurements provide a useful indication of an Antarctic programme's regional sphere of influence, of inviolate areas, and of areas exposed to the potential for introduction of species, but are of little use if they do not convey varying intensity of impacts. However, there are many specific forms of footprint that are based on empirical data from measurable impacts. These have been mapped for the facilities of several Antarctic programmes, but scarcely for tourism. Although some forms of footprint are not as evident for the majority of Antarctic tourism as they are for national programmes (e.g. buildings), or are more transient, evidence of cumulative disturbance footprints such as that found by Tejedo et al. (2016), and external calls for assessment (ASOC 2012), suggest that impacts from tourism should be included in footprint assessments.

\section{Conclusion}

Unlike any other continent, Antarctica presents the unique opportunity to quantify human activity and disturbance by where it occurs, as opposed to where it does not. Effectively the inverse of wilderness area, footprint has become the term used to quantify those areas of Antarctica affected by human activity. Using clear terminology for the various types of footprints should eventually lead to the development of consistent footprint datasets that will support management activity and decision making. We propose that footprint prefixes are used hereafter to ensure clarity by describing the context under consideration. The use of the general term human footprint to describe a specific type of impact should be avoided, but may be used as a unifying concept for many types of footprints. Moving towards more consistent applications of the term footprint in Antarctica will help progress the use of footprint measurements and improve awareness and communication of impacts to Antarctic programmes, policymakers, scientists, and onthe-ground operators. Furthermore, a useful working definition and understanding of footprint may help in moving towards a common approach to the terms 'minor' and 'transitory', which are significant to the Madrid Protocol's regulation of environmental impacts.

\section{Acknowledgements}

Tom Maggs provided support in original concept development. We dedicate this paper to his memory. S.T. Brooks is supported by an Australian Government Research Training Program Scholarship. Tim Spedding and Dan Wilkins provided assistance with hydrocarbon spill information for Casey Station. We also thank Phil Tracey, David Walton, Ricardo Roura, and two anonymous reviewers for their thought-provoking feedback and valuable suggestions.

\section{Author contributions}

S.T. Brooks led the conceptual development and writing of the paper. Drs J. Jabour and D.M. Bergstrom contributed to conceptual and content development, expert advice, and drafting and revisions of the manuscript.

\section{References}

ASOC (Antarctic and Southern Ocean Coalition) 2012. Follow-up to vessel incidents in Antarctic waters, Information Paper 53 for XXXV Antarctic Treaty Consultative Meeting.

ASOC (Antarctic and Southern Ocean Coalition) 2014. Managing human footprint, protecting wilderness: a way forward, Information Paper 071 for XXXVII Antarctic Treaty Consultative Meeting.

Australia 2002. Antarctic state of the environment reporting, Information Paper 054 for XXV Antarctic Treaty Consultative Meeting, Warsaw. Australia 2010. Topic summary: footprint, Information Paper 048 for XXXIII Antarctic Treaty Consultative Meeting, Punta del Este.

Ayres, E., Nkem, J.N., Wall, D.H., Adams, B.J., Barrett, J.E., Broos, E.J., Parsons, A.N., Powers, L.E., Simmons, B.L. \& VIRGINIA, R.A. 2008. Effects of human trampling on populations of soil fauna in the McMurdo Dry Valleys, Antarctica. Conservation Biology, 22, 10.1111/j.1523-1739.2008.01034.x.

Belgium 2006. Construction and operation of the new Belgian Research Station in Dronning Maud Land, Antarctica. Draft Comprehensive Environmental Evaluation (CEE), Working Paper 025 for XXIX Antarctic Treaty Consultative Meeting, Edinburgh.

Belgium, South Africa, United Kingdom \& SCAR 2013. Human footprint in Antarctica and the long-term conservation of terrestrial microbial habitats, Working Paper 039 for XXXVI Antarctic Treaty Consultative Meeting, Brussels.

Bollard-Breen, B., Brooks, J.D., Jones, M.R.L., Robertson, J., Betschart, S., Kung, O., Craig Cary, S., Lee, C.K. \& Pointing, S.B. 2014. Application of an unmanned aerial vehicle in spatial mapping of terrestrial biology and human disturbance in the McMurdo Dry Valleys, East Antarctica. Polar Biology, 38, 573-578. 
BRooks, S.T. 2014. Developing a standardised approach to measuring the environmental footprint of Antarctic research stations. Journal of Environmental Assessment Policy and Management, 16, 10.1142/ S1464333214500379.

Burton-Johnson, A., Black, M., Fretwell, P.T. \& Kaluza-Gilbert, J. 2016. An automated methodology for differentiating rock from snow, clouds and sea in Antarctica from Landsat 8 imagery: a new rock outcrop map and area estimation for the entire Antarctic continent. The Cryosphere, 10, 10.5194/tc-10-1665-2016.

Campbell, I.B., Claridge, G.G.C. \& Balks, M.R. 1998. Short- and long-term impacts of human disturbances on snow-free surfaces in Antarctica. Polar Record, 34, 10.1017/S0032247400014935.

CEP (Committee for Environmental Protection) 2010. Report of the Committee for Environmental Protection (XIII). XXXIII Antarctica Treaty Consultative Meeting, Punta del Este.

CHINA 2008. The Draft Comprehensive Environmental Evaluation for the construction and operation of the Chinese Dome A Station in Antarctica, Working Paper 005 for XXXI Antarctic Treaty Consultative Meeting, Kyiv.

Conlon, K.E., Rau, G.H. \& Kvitek, R.G. 2006. $813 \mathrm{C}$ and $815 \mathrm{~N}$ shifts in benthic invertebrates exposed to sewage from McMurdo Station, Antarctica. Marine Pollution Bulletin, 52, 10.1016/j.marpolbul. 2006.06.010.

Cowan, D.A., Chown, S.L., Convey, P., Tuffin, M., Hughes, K., Pointing, S. \& Vincent, W.F. 2011. Non-indigenous microorganisms in the Antarctic: assessing the risks. Trends in Microbiology, 19, 10.1016/j.tim.2011.07.008.

DAvis, G.A. 2017. A history of McMurdo Station through its architecture. Polar Record, 53, 10.1017/S0032247416000747.

FALLON, L.D. \& KRIWOKEN, L.K. 2005. Environmental impact assessment under the Protocol on Environment Protection to the Antarctic Treaty and Australian legislation. Macquarie Journal of International and Comparative Environmental Law, 2, 67-103.

Farreny, R., Oliver-Solà, J., Lamers, M., Amelung, B., Gabarrell, X., Rieradevall, J., Boada, M. \& Benayas, J. 2011. Carbon dioxide emissions of Antarctic tourism. Antarctic Science, 23, 10.1017/S0954 102011000435.

Fryirs, K., Snape, I. \& Babicka, N. 2013. The type and spatial distribution of past waste at the abandoned Wilkes Station, East Antarctica. Polar Record, 49, 10.1017/S0032247412000721.

Galera, H., Wódkiewicz, M., Czyż, E., Łapiński, S., Kowalska, M.E., Pasik, M., Rajner, M., Bylina, P. \& ChwedorzewsKa, K.J. 2016. First step to eradication of Poa аппи $\mathrm{L}$. from Point Thomas Oasis (King George Island, South Shetlands, Antarctica). Polar Biology, 40, 939-945.

Goldsworthy, P., Canning, E. \& Riddle, M. 2003. Soil and water contamination in the Larsemann Hills, East Antarctica. Polar Record, 39, 10.1017/S003224740300305X.

Howington, J.P., McFeters, G.A., Barry, J.P. \& Smith, J.J. 1992. Distribution of the McMurdo Station sewage plume. Marine Pollution Bulletin, 25, 10.1016/0025-326X(92)90690-8.

Hughes, K.A. 2010. How committed are we to monitoring human impacts in Antarctica? Environmental Research Letters, 5, 041001.

Hughes, K.A., Cowan, D.A. \& Wilmotte, A. 2015. Protection of Antarctic microbial communities - 'out of sight, out of mind'. Frontiers in Microbiology, 6, 151.

Hughes, K.A., Fretwell, P., Rae, J., Holmes, K. \& Fleming, A. 2011. Untouched Antarctica: mapping a finite and diminishing environmental resource. Antarctic Science, 23, 10.1017/S095410201100037X.

Hughes, K.A. \& Worland, M.R. 2010. Spatial distribution, habitat preference and colonization status of two alien terrestrial invertebrate species in Antarctica. Antarctic Science, 22, 10.1017/S0954102009990770.

Hull, B. \& Bergstrom, D. 2006. Antarctic terrestrial and limnetic ecosystem conservation and management. In Bergstrom, D.M., Convey, P. \& Huiskes, A.H.L., eds. Trends in Antarctic terrestrial and limnetic ecosystems. Dordrecht: Springer, 317-340.
JABOUR, J. 2009. National Antarctic programs and their impact on the environment. In Kerry, K.R. \& Riddle, M.J., eds. Health of Antarctic wildlife: a challenge for science and policy. Dordrecht: Springer, 211-229.

Kennicutt II, M.C., Klein, A., Montagna, P., Sweet, S., Wade, T., Palmer, T., Sericano, J. \& Denoux, G. 2010. Temporal and spatial patterns of anthropogenic disturbance at McMurdo Station, Antarctica. Environmental Research Letters, 5, 034010.

Klein, A.G., Kennicutt, M.C., WolfF, G.A., Sweet, S.T., Bloxom, T., Gielstra, D.A. \& Cleckley, M. 2008. The historical development of McMurdo station, Antarctica, an environmental perspective. Polar Geography, 31, 10.1080/10889370802579856.

Klein, A.G., Sweet, S.T., Wade, T.L., Sericano, J.L. \& Kennicutt, M.C. 2012. Spatial patterns of total petroleum hydrocarbons in the terrestrial environment at McMurdo Station, Antarctica. Antarctic Science, 24, 10.1017/S0954102012000429.

KRIWOKEN, L.K. 1991. Antarctic environmental planning and management: conclusions from Casey, Australian Antarctic Territory. Polar Record, 27, 10.1017/S0032247400019793.

McWatters, R.S., Wilkins, D., Spedding, T., Hince, G., Raymond, B., Lagerewskij, G., Terry, D., Wise, L. \& Snape, I. 2016. On site remediation of a fuel spill and soil reuse in Antarctica. Science of the Total Environment, 571, 10.1016/j.scitotenv.2016.07.084.

New Zealand 2010. The concept of Human Footprint in the Antarctic. Information Paper 49 for XXXIII Antarctic Treaty Consultative Meeting, Punta del Este.

New Zealand 2011. Understanding concepts of Footprint and Wilderness related to protection of the Antarctic environment, Working Paper 035 for XXXIV Antarctic Treaty Consultative Meeting, Buenos Aires.

O’Neill, T.A., Balks, M.R. \& López-Martínez, J. 2013. Visual recovery of desert pavement surfaces following impacts from vehicle and foot traffic in the Ross Sea region of Antarctica. Antarctic Science, 25, 10.1017/S0954102012001125.

Pertierra, L.R., Hughes, K.A., Vega, G.C. \& Olalla-Tarraga, M. A. 2017. High resolution spatial mapping of human footprint across Antarctica and its implications for the strategic conservation of avifauna. PLoS ONE, 12, 10.1371/journal.pone. 0168280.

Pertierra, L.R., Lara, F., Benayas, J. \& Hughes, K.A. 2013. Poa pratensis L., current status of the longest-established non-native vascular plant in the Antarctic. Polar Biology, 36, 1473-1481.

Raymond, T., King, C.K., Raymond, B., Stark, J.S. \& Snape, I. 2016. Oil pollution in Antarctica. In FINGAS, M., ed. Oil spill science and technology, 2nd ed. Cambridge, MA: Elsevier, 759-804.

ReEs, W.E. 1992. Ecological footprints and appropriated carrying capacity: what urban economics leaves out. Environment and Urbanization, 4, 10.1177/095624789200400212.

Rothwell, D.R. 2000. Polar environmental protection and international law: The 1991 Antarctic protocol. European Journal of International Law, 11, 10.1093/ejil/11.3.591.

RourA, R. 2004. Monitoring and remediation of hydrocarbon contamination at the former site of Greenpeace's World Park Base, Cape Evans, Ross Island, Antarctica. Polar Record, 40, 10.1017/ S0032247403003292.

Roura, R.M. 2011. The footprint of polar tourism: tourist behaviour at cultural heritage sites in Antarctica and Svalbard. Circumpolar Studies, No. 7. Eelde, Netherlands: Barkhuis, 306 pp.

Sanderson, E.W., Jaiteh, M., Levy, M.A., Redford, K.H., Wannebo, A.V. \& Woolmer, G. 2002. The Human Footprint and the Last of the Wild: the human footprint is a global map of human influence on the land surface, which suggests that human beings are stewards of nature, whether we like it or not. BioScience, 52, 10.1641/0006-3568(2002)052 [0891:THFATL]2.0.CO;2. 
Summerson, R. 2012. Protection of wilderness and aesthetic values in Antarctica. In Huettmann, F., ed. Protection of the three poles. New York: Springer, 77-109.

Summerson, R. \& Bishop, I.D. 2012. The impact of human activities on wilderness and aesthetic values in Antarctica. Polar Research, 31, 10.3402/polar.v31i0.10858.

Summerson, R. \& Tin, T. 2009. Protection of the wilderness and aesthetic values of Antarctica: Geographical Information Systems (GIS) as a tool. In Watson, A., Sproull, J. \& Dean, L., eds. Science and stewardship to protect and sustain wilderness values. Ninth World Wilderness Congress Symposium, Meridá, Mexico. Fort Collins, CO: U.S. Department of Agriculture, Forest Service, Rocky Mountain Research Station, 6-13.

Tejedo, P., Benayas, J., Cajiao, D., Albertos, B., Lara, F., Pertierra, L.R., Andres-Abellan, M., Wic, C., Lucianez, M.J., Enriquez, N., Justel, A. \& ReCK, G.K. 2016. Assessing environmental conditions of Antarctic footpaths to support management decisions. Journal of Environmental Management, 177, 10.1016/j.jenvman.2016.04.032.

Terauds, A., Chown, S.L., Morgan, F., Peat, H.J., Watts, D.J., Keys, H., Convey, P. \& Bergstrom, D.M. 2012. Conservation biogeography of the Antarctic. Diversity and Distributions, 18, 10.1111/j.1472-4642.2012.00925.x.
Tin, T., Fleming, Z.L., Hughes, K.A., Ainley, D.G., Convey, P., Moreno, C.A., Pfeiffer, S., Scott, J. \& Snape, I. 2009. Impacts of local human activities on the Antarctic environment. Antarctic Science, 21, 10.1017/S0954102009001722.

UNITED STATES 1998. Developing an environmental monitoring program a work in progress, Information Paper 034 for XXII Antarctic Treaty Consultative Meeting, Tromso.

United States 2003. Final report from the intersessional contact group on cumulative environmental impacts. Working Paper 006 for XXVI Antarctic Treaty Consultative Meeting, Madrid.

United States 2007. Draft management plan for ASMA No. X: Amundsen-Scott South Pole Station, South Pole. Management Plan ASMA South Pole. Working Paper 003 for XXX Antarctic Treaty Consultative Meeting New Delhi.

Walton, D.W.H. \& Shears, J. 1994. The need for environmental monitoring in Antarctica: Baselines, environmental impact assessments, accidents and footprints. International Journal of Environmental Analytical Chemistry, 55, 10.1080/0306731940 8026210 .

Wiedmann, T. \& MinX, J. 2008. A definition of 'carbon footprint'. In Pertsova, C.C., ed. Ecological economics research trends. Hauppauge, NY: Nova Science Publishers, 1-11. 